\title{
Analysis on the Problems of Rational Drug Use Carrying Out by Hospital Pharmacists in China
}

\author{
Han Yang, Yongfa Chen* \\ School of International Pharmaceutical Business, China Pharmaceutical University, Nanjing, China \\ Email: *cyf990@163.com
}

How to cite this paper: Yang, $H$. and Chen, Y.F. (2021) Analysis on the Problems of Rational Drug Use Carrying Out by Hospital Pharmacists in China. Open Journal of Preventive Medicine, 11, 251-258. https://doi.org/10.4236/ojpm.2021.116020

Received: May 6, 2021

Accepted: June 15, 2021

Published: June 18, 2021

Copyright (c) 2021 by author(s) and Scientific Research Publishing Inc. This work is licensed under the Creative Commons Attribution International License (CC BY 4.0).

http://creativecommons.org/licenses/by/4.0/ (c) (i) Open Access

\begin{abstract}
Pharmacists are the implementers of clinical drug management, and they play an irreplaceable role in promoting the improvement of rational drug use. However, the current role of pharmacists in the supervision and protection of rational drug use has not been fully exerted. This article is aimed to investigate the current situation of pharmacists' work of rational drug use from the perspectives of pharmacists, physicians, and patients. It is found that the professional value of pharmacists in the rational drug use has not been valued by medical institutions, physicians, and patients. Pharmacists face problems such as workload, working conditions, and doctor-patient cooperation in the rational drug use. Suggestions are made for further exerting the professional value of pharmacists in promoting the level of rational drug use. Relevant managers should pay full attention to the professional value of pharmacists, and provide corresponding system and facility guarantees for pharmacists to carry out rational drug use.
\end{abstract}

\section{Keywords}

Hospital Pharmacist, Rational Drug Use, Investigation and Analysis

\section{Introduction}

The rational drug use is an important part of the national essential drug policy, directly related to the quality of medical care for patients and the vital interests of the general public. The "Several Opinions on Further Reforming and Improving Policies for the Production, Distribution and Use of Drugs" issued by the General Office of the State Council clearly stated that it is necessary to "give full play to the role of pharmacists in the rational use of drugs." Pharmacists are the implementers of clinical medication management and play an indispensable and key role in the rational use of medications. This study investigates the prob- 
lems encountered by pharmacists in the rational drug use from multiple perspectives of pharmacists, physicians and patients, and provides suggestions for pharmacists to play the professional value of promoting the level of rational use of drugs.

\section{Materials and Methods}

\subsection{Source of Information}

From April 1, 2021 to April 15, 2021, a combination of the online questionnaires and paper questionnaires was used to investigate the current situation of rational drug use by hospital pharmacists, physicians, and patients.

\subsection{Questionnaire Design}

Design a questionnaire based on relevant literature [1] [2] [3] [4] [5], and distribute questionnaires to hospital pharmacists, physicians, and patients. The main contents of the questionnaire for pharmacists are: the basic situation of the survey object, the development of rational drug use, and the problems existing in the development of rational drug use; the main content of the questionnaire for physicians and patients is: the basic information of the survey object, the level of cognition with pharmacists and the level of cooperation with pharmacists.

\section{Results}

\subsection{Source of Materials}

We conducted a survey of doctors, pharmacists and patients in hospitals in Jiangsu Province by combining online and offline questionnaires. A total of 223 questionnaires were collected, of which 130 were from hospital pharmacists, 63 were from physicians, and 130 were from patients.

\subsection{The Current Situation of Hospital Pharmacists' Rational Drug Use Work}

This study investigated the implementation of rational drug use by pharmacists at all levels of hospitals. A total of 130 questionnaires were returned, of which 78 were from third-level hospital pharmacists, 9 were from second-level hospital physicians, and 43 were from first-level hospital pharmacists.

The top three pharmaceutical service projects carried out by pharmacists are prescription review and comment, patient medication guidance, and adverse drug reaction monitoring. The frequency of assisting doctors in medication tracking is the lowest. The current situation of rational drug use carried out by hospital pharmacists is shown in Table 1.

The main difficulties encountered by pharmacists in the process of rational drug use in hospitals at all levels are: lack of time to conduct prescription review and medication guidance, poor patient compliance, and inability to conduct individualized medication guidance based on the detailed conditions of patients. 
Table 1. The current situation of rational drug use carried out by hospital pharmacists.

\begin{tabular}{lccc}
\hline & \multicolumn{3}{c}{ Hospital level } \\
\cline { 2 - 4 } \multicolumn{1}{c}{ Pharmaceutical Services Project } & $\begin{array}{c}\text { third-level } \\
\text { hospital }\end{array}$ & $\begin{array}{c}\text { second-level } \\
\text { hospital }\end{array}$ & $\begin{array}{c}\text { first-level } \\
\text { hospital }\end{array}$ \\
\hline Prescription review and comment & 74 & 7 & 28 \\
Patient medication guidance & 71 & 3 & 28 \\
Adverse drug reaction monitoring & 70 & 4 & 24 \\
Propaganda of rational drug use knowledge & 56 & 3 & 20 \\
Assist doctors in medication tracking & 54 & 5 & 11 \\
Participate in the supervision of rational drug use & 66 & 4 & 21 \\
Organize training and assessment of rational & 16 & 5 & 18 \\
drug use & & & \\
\hline
\end{tabular}

The problems and reasons of pharmacists' rational use of drugs are shown in Table 2.

\subsection{Physicians' Cognitive and Cooperation with Pharmacists}

In this study, a total of 63 questionnaires were collected about physicians' cognitive and cooperation with pharmacists, of which 29 were from physicians in third-level hospitals, 6 were from physicians in second-level hospitals, and 28 were from physicians in first-level hospitals.

In the survey of physicians' cognition and cooperation with pharmacists, $57.14 \%$ of physicians believe that the primary job of pharmacists is to ensure the supply of medicines, and less than $30 \%$ of physicians believe that the first person responsible for prescription review is the pharmacist. $92.06 \%$ of physicians encountered pharmacists communicating with patients about medication problems, but only $53.97 \%$ of those who adopted the prescription modification suggestions put forward by pharmacists. Among the doctors interviewed, $92.06 \%$ of the doctors believed that the degree of trust in the professional level of the pharmacist's medication was the most important factor affecting the degree of cooperation with the pharmacist. The details of physicians' cognitive and cooperation with pharmacists are shown in Table 3.

\subsection{The Public's Cognition and Cooperation with Pharmacists}

In this study, 130 questionnaires were returned to investigate the public's cognition and cooperation with pharmacists.

In the survey of public awareness and cooperation with pharmacists, only $30.77 \%$ of patients knew that pharmacists have the responsibility to participate in the formulation of patient medication regimens; they choose to consult pharmacists when they have doubts about drug use. Less than $30 \%$ of the public fully trust that pharmacists can promote the level of rational drug use; more than half of the public believe that the degree of trust in the professional level of pharmacists and their cognition of the pharmacist profession are the main 
Table 2. The problems and reasons of pharmacists' rational drug use.

\begin{tabular}{|c|c|c|}
\hline Question & Alternative Answer & Frequency \\
\hline $\begin{array}{l}\text { 1) What factors do you think are } \\
\text { related to the degree of } \\
\text { cooperation between doctors and } \\
\text { patients in the pharmacists' } \\
\text { rational drug use work } \\
\text { (multiple choices available): }\end{array}$ & $\begin{array}{l}\text { Whether there are laws, regulations } \\
\text { and system guarantees; Related to the } \\
\text { status of patients and doctors, such as } \\
\text { whether the body is unwell, whether } \\
\text { the workload is too large, etc.; } \\
\text { Related to the ability to } \\
\text { communicate with the pharmacist; } \\
\text { the professional identity of the } \\
\text { pharmacist; The trust degree of } \\
\text { the pharmacist; Other }\end{array}$ & $\begin{array}{l}99 ; 93 ; 80 ; 88 ; 99 ; \\
1\end{array}$ \\
\hline $\begin{array}{l}\text { 2) The practical difficulties you } \\
\text { encountered in the } \\
\text { implementation of rational } \\
\text { drug use are as follows } \\
\text { (multiple choices are available): }\end{array}$ & $\begin{array}{l}\text { The workload of drug preparation is } \\
\text { heavy, and there is no time to } \\
\text { conduct prescription review and } \\
\text { medication guidance; Patient } \\
\text { compliance is poor; Doctors do } \\
\text { not cooperate; It is not possible to } \\
\text { conduct individualized medication } \\
\text { guidance based on the patient's } \\
\text { details; Others }\end{array}$ & $95 ; 94 ; 59 ; 71 ; 3$ \\
\hline $\begin{array}{l}\text { 3) What do you think is the } \\
\text { reason for the above difficulties } \\
\text { (multiple choices are available): }\end{array}$ & $\begin{array}{l}\text { The legal system is not perfect; } \\
\text { The hospital-related rational drug } \\
\text { management system is not perfect; } \\
\text { The hardware equipment and } \\
\text { software facilities are insufficient; } \\
\text { The staff is insufficient and the } \\
\text { staffing is unreasonable; Doctors lack } \\
\text { understanding and trust in the work } \\
\text { of pharmacists; Patients lack } \\
\text { understanding and trust in the work } \\
\text { of pharmacists; Lack Corresponding } \\
\text { training has led to a mismatch } \\
\text { between pharmacy knowledge } \\
\text { structure and the requirements of } \\
\text { rational drug use; Lack of enthusiasm } \\
\text { and motivation for work; Other }\end{array}$ & $\begin{array}{l}81 ; 75 ; 54 ; 91 ; 75 ; \\
89 ; 70 ; 25 ; 2\end{array}$ \\
\hline
\end{tabular}

reasons that affect their cooperation with pharmacists. The details of physicians' cognitive and cooperation with pharmacists are shown in Table 4.

\section{Discussion}

\subsection{The Role of Pharmacists in Guiding Patients to Rational Use of Drugs Has Not Been Fully Utilized}

At present, because medical institutions do not pay enough attention to the rational use of drugs by pharmacists, it is difficult for pharmacists to review and comment on prescriptions and guide medication. According to the survey results, $83.85 \%$ of hospital pharmacists frequently conduct prescription review and review, which did not meet the requirement of "Prescriptions can be paid and adjusted after review" stipulated in the "Specifications for Prescription Review of Medical Institutions". The overall regular rate of patient medication guidance 
Table 3. The physicians' cognitive and cooperation with pharmacists.

\begin{tabular}{|c|c|c|}
\hline Question & Alternative Answer & Frequency \\
\hline $\begin{array}{l}\text { 1) Which do you think is the primary } \\
\text { task of a pharmacist: }\end{array}$ & $\begin{array}{l}\text { Drug allocation and distribution to } \\
\text { ensure drug supply; Participate in the } \\
\text { formulation of patient drug } \\
\text { treatment plans; Review and } \\
\text { comment on prescriptions } \\
\text { and medical orders }\end{array}$ & $\begin{array}{l}36 ; 3 ; 21 ; 2 ; 0 ; \\
1\end{array}$ \\
\hline $\begin{array}{l}\text { 2) In your opinion, the first person } \\
\text { responsible for prescription review is: }\end{array}$ & Physician; Pharmacist & $46 ; 17$ \\
\hline $\begin{array}{l}\text { 3) Your attitude towards the } \\
\text { prescription modification proposal } \\
\text { put forward by the pharmacist is: }\end{array}$ & $\begin{array}{l}\text { Adopted; Partially Adopted; } \\
\text { Not Adopted }\end{array}$ & $34 ; 29 ; 0$ \\
\hline $\begin{array}{l}\text { 4) Has the pharmacist communicated } \\
\text { with you about the patient's rational } \\
\text { use of drugs: }\end{array}$ & Yes; No & $58 ; 5$ \\
\hline $\begin{array}{l}\text { 5) Is your communication with the } \\
\text { pharmacist smooth: }\end{array}$ & $\begin{array}{l}\text { Smooth; Relatively smooth; Not } \\
\text { very smooth; Not smooth }\end{array}$ & $39 ; 22 ; 1 ; 1$ \\
\hline $\begin{array}{l}\text { 6) The reasons that affect your } \\
\text { cooperation with the pharmacist } \\
\text { are (multiple choices available): }\end{array}$ & $\begin{array}{l}\text { The level of trust in the professional } \\
\text { level of the pharmacist; The degree of } \\
\text { recognition of the pharmacist's } \\
\text { profession; Whether the } \\
\text { communication with the } \\
\text { pharmacist is pleasant; The } \\
\text { attitude of other medical staff } \\
\text { to the pharmacist; Others }\end{array}$ & $\begin{array}{l}58 ; 43 ; 34 ; 18 ; \\
0\end{array}$ \\
\hline
\end{tabular}

was $78.46 \%$, of which $91.02 \%$ were pharmacists in tertiary hospitals, $33.33 \%$ were pharmacists in second-level hospitals, and $65.11 \%$ in first-level hospitals. From the results, the development rate of prescription review and comment and patient medication guidance in first-level and second-level hospitals is relatively low, showing that the third-level hospitals are better than the first-level and second-level hospitals. The role of pharmacists in guiding patients to rational use of drugs has not yet played out.

Carrying out prescription review and comment is the core link of rational drug use, and it is also a necessary link for pharmacists to effectively manage clinical drugs and improve the quality of medical services [6]. Medical institutions should attach importance to prescription review and prescription review, and formulate unified and standard management documents to promote the standardized implementation of prescription review and prescription review. At the same time, providing individualized medication guidance is the last link of "patient-centered" pharmaceutical care, which can ensure the safety of patients' medication and improve the level of clinical rational medication [7] [8]. Medical institutions should standardize the rules, regulations and procedures for medication accountability and guidance, which will help pharmacists to further fulfill their responsibilities, provide pharmaceutical services closer to patients, and improve patient medication compliance. 
Table 4. The public's cognitive and cooperation with pharmacists.

\begin{tabular}{|c|c|c|}
\hline Question & Alternative Answer & Frequency \\
\hline $\begin{array}{l}\text { 1) Do you know what the } \\
\text { pharmacist's work includes } \\
\text { (multiple choices available): }\end{array}$ & $\begin{array}{l}\text { Drug dispensing and distribution; } \\
\text { Review and comment on } \\
\text { prescriptions; Participate in the } \\
\text { formulation of patient drug } \\
\text { treatment plans; Medication } \\
\text { guidance; Adverse reaction } \\
\text { monitoring; Others }\end{array}$ & $\begin{array}{l}112 ; 74 ; 40 ; 89 ; \\
35 ; 11\end{array}$ \\
\hline $\begin{array}{l}\text { 2) Do you think the job of a } \\
\text { pharmacist can be replaced by } \\
\text { other medical staff such as } \\
\text { doctors and nurses: }\end{array}$ & Yes; No & $27 ; 103$ \\
\hline $\begin{array}{l}\text { 3) Your level of trust in pharmacists' } \\
\text { promotion of rational drug use: }\end{array}$ & $\begin{array}{l}\text { Completely trust; More trust; } \\
\text { half-trusted; don't believe }\end{array}$ & $39 ; 77 ; 13 ; 1$ \\
\hline $\begin{array}{l}\text { 4) If you have doubts about the use } \\
\text { of drugs, whom you will choose to } \\
\text { consult: }\end{array}$ & Physician; Pharmacist; Nurse; Other & $91 ; 36 ; 2 ; 1$ \\
\hline $\begin{array}{l}\text { 5) When the pharmacist tells you that } \\
\text { there is a problem with the } \\
\text { prescription issued by the doctor } \\
\text { and you need to see the doctor } \\
\text { to revise it, you will: }\end{array}$ & $\begin{array}{l}\text { Follow the arrangement of the } \\
\text { pharmacist and talk to the doctor; } \\
\text { Go if the pharmacist has a good } \\
\text { attitude; You don't want to go but } \\
\text { there is no way, you can't get the } \\
\text { medicine if you don't go; Resolutely } \\
\text { don't go, Only take medicine; others }\end{array}$ & $113 ; 4 ; 6 ; 1 ; 6$ \\
\hline $\begin{array}{l}\text { 6) The reasons that affect your } \\
\text { cooperation with the pharmacist } \\
\text { are (multiple choices available): }\end{array}$ & $\begin{array}{l}\text { The level of trust in the professional } \\
\text { level of the pharmacist; The degree } \\
\text { of recognition of the pharmacist's } \\
\text { profession; Whether the } \\
\text { communication with the pharmacist } \\
\text { is pleasant; The attitude of other } \\
\text { medical staff to the pharmacist; } \\
\text { Others }\end{array}$ & $\begin{array}{l}96 ; 72 ; 48 ; 23 ; \\
9\end{array}$ \\
\hline
\end{tabular}

\subsection{The Communication Channels between Pharmacists and Doctors and Patients Need to Be Broadened}

As the demand for pharmacy services increases, hospital pharmacy services are also transforming, gradually moving from behind the clinical diagnosis and treatment of patients to the front stage, and pharmacists are also gradually changing their job positioning, from dispensing pharmacists to clinical pharmacists, participating with clinicians Treatment of patients. But at present, pharmacists are less active in the process of clinical participation and lack communication and cooperation with doctors. As doctors dominate the diagnosis and treatment activities, most patients and their families have insufficient understanding of the important position and functions of pharmacists, and their understanding of pharmacists is still at the stage of traditional hospital pharmacy, which mainly focused on the supply of medicines.

Broadening the communication channels between pharmacists, physicians 
and patients in daily diagnosis and treatment activities can effectively improve the cooperation between physicians and patients [9]. It is recommended that medical institutions increase the real-time interactive function of the relevant rational drug use management system to facilitate pharmacists to provide necessary professional pharmacy support to enhance the understanding and trust between pharmacists and physicians; at the same time, an Internet communication platform between pharmacists and patients can be opened for the convenience of patients inquire about prescription information, drug usage and dosage, precautions and other pharmaceutical information. This will also indirectly urge pharmacists to continuously improve their professional skills and humanistic qualities, and actively carry out pharmaceutical services to effectively make up for the omission of doctor-patient communication.

\subsection{The Construction of Pharmaceutical Informatization Still Needs to Be Improved}

Since the full implementation of the zero-markup policy for drugs, the pharmacy department of hospitals has been transformed into a cost department. In order to ensure the interests of hospitals, many hospitals have paid less attention to pharmacies and pharmacists that currently cannot bring great economic benefits to the hospital. The investment in hardware and software facilities cannot meet the needs of pharmaceutical services. $41.54 \%$ of the pharmacists in the survey believed that the lack of hardware equipment and software facilities made them lack detailed patient information and could not conduct individualized medication guidance, which hindered the normal development of clinical rational drug use. Due to differences in facility conditions, technical capabilities, and fund investment, there are differences in the level of development of rational drug use among hospitals.

Information technology plays an important role in the management of all walks of life [10]. As an indispensable department in the medical system, the hospital pharmacy should conform to the current development trend of information technology and continuously strengthen its own information construction and management. Promoting the Pharmaceutical informatization construction of can reduce the workload of pharmacists to a certain extent and improve the quality of pharmacists' work under the premise of ensuring reasonable drug use. It is recommended that medical institutions pay attention to the construction of Pharmaceutical informatization, and effectively integrate information technology into the links of prescription review, drug preparation, and medication guidance, so as to improve the full-course and timeliness of pharmacy services.

\section{Conclusion}

Pharmacists are the implementers of clinical drug management, and they play an irreplaceable role in promoting the improvement of rational drug use and re- 
ducing the waste of medical resources. The survey found that the role of pharmacists in promoting rational drug use needs to be popularized. Mobilizing the enthusiasm and creativity of pharmacists to play their due functions and duties in medical work is necessary for the rationality, standardization, safety and effectiveness of clinical medication. Medical institutions must pay sufficient attention to the professional value of pharmacists in the rational drug use, and provide necessary management system guarantees and related facility support for pharmacists to carry out pharmaceutical services.

\section{Conflicts of Interest}

The authors declare no conflicts of interest regarding the publication of this paper.

\section{References}

[1] Zhang, D.D., Yang, Q.Y. and Jin, H.Y. (2013) Investigation and Analysis of Demand for Clinical Pharmacy Services by Doctors, Nurses and Patients. China Pharmacy, 24, 1839-1842.

[2] Li, L.X., Wang, Q.L. and Wu, H.Y. (2015) Analysis of Questionnaire Survey on Reasonable Drug Use Knowledge of Hospital First-Line Pharmacists. China Pharmaceuticals, 16, 1839-1842.

[3] Chen, W.Y., Cai, W.G. and Ma, G. (2017) Investigation and Research on the Cognition and Needs of Patients and Their Families on Clinical Pharmacists and Pharmaceutical Services. China Journal of Hospital Pharmacy, 37, 2490-2495.

[4] Wu, X.X., Sun, S.Y., Wang, Q.F., et al. (2019) Analysis of Reasons for Irrational Use of Antibacterial Drugs and Intervention Research. Journal of Clinical Medical Literature (Electronic Edition), 6, 170-171.

[5] Gao, C.C. and Xue, H.T. (2020) Analysis of the Current Situation and Influencing Factors of Unreasonable Drug Use in Hospitals. Guangming Journal of Chinese Medicine, 35, 2930-2932.

[6] Xie, S.S., Liu, S., Wang, J.J., et al. (2021) Pharmacists Use Reasonable Drug Software to Carry out the Practice and Effect of Pre-review of Emergency Prescriptions. China Pharmacy, 32, 876-880.

[7] Zhu, X.Y. (2020) A Study on Inpatient Drug Consultation in Primary Medical Institutions from 2014 to 2019. Chinese Journal of Rational Drug Use, 17, 23-25.

[8] Gao, Y.Y., Guo, Y., Wang, S.Y., et al. (2021) The Practice and Discussion of Pharmacist's Drug Accounting and Guiding Service Ability Improvement. West China Journal of Pharmaceutical Sciences, 36, 233-236.

[9] Ren, Y.H. (2020) The Effect of the Out-Patient Pharmacy Window of a Hospital on the Rational Drug Use and Efficacy of Drug Delivery and Pharmacy Service Guidance. Anti-Infection Pharmacy, 17, 833-836.

[10] Wang, Y.Y. (2021) Discussion on the Information Management Measures of the Western Pharmacy of the Hospital Outpatient Clinic. Modern Hospital Management, 19, 85-87. 